\title{
Gender Differences in Experiencing US Daily Life
}

\author{
John P. Robinson \\ University of Maryland, College Park, USA \\ Email: jpr@umd.edu
}

Received 24 February 2014; revised 21 March 2014; accepted 18 April 2014

Copyright (C) 2014 by author and Scientific Research Publishing Inc.

This work is licensed under the Creative Commons Attribution International License (CC BY).

http://creativecommons.org/licenses/by/4.0/

(c) (i) Open Access

\section{Abstract}

The American Time-Use Survey (ATUS), conducted by the US Bureau of the Census for the Bureau of Labor Statistics, has been collecting data on how Americans spend their time since 2003, using the method of the daily time diary. In these diaries, survey respondents are asked to recall all of their activities across the previous 24 hours. In 2010, the ATUS began supplementing these simple activity accounts with ratings on five psychological states (sad, tired, stress, pain and happy) from a Social Well-Being (SWB) index designed to capture how these respondents feel as they engage in these daily activities. Thus, this ATUS study basically provides a continuous national monitor of Americans' everyday subjective quality of life (QOL) - and in "real time" as personally experienced by respondents. Analysis of these 2010-12 ATUS SWB ratings from more than 12,000 Americans aged 15 and older reveal that women score significantly higher than men on all five factors, even though only one of the adjectives (happy) was in the positive direction. Thus, US women described their daily activities as more stressful, tiring, sad and painful, but at the same time also describing their activities as making them feel happier (suggesting that women see their lives as more engaging, intense or energizing). In order to control for this gender difference, a simple scale was derived from two of the items that conveyed basically the same emotional state, namely happy and sad. When these ratings on two items were paired, virtually no gender difference was found; nor were many gender differences found when they rated these feelings on the same activity. However, there were dramatic subjective differences across activities that were largely shared by both men and women, with child play, religious, volunteer and fitness activities rated near the top of enjoyment and with medical, housework and work activities nearer the bottom. These results seem generally consistent with enjoyment ratings in earlier national time-use surveys.

\section{Keywords}

Positively Experiencing, SWB 


\section{Background}

Over the last the last 50 years, society has undergone a continual gender revolution, one that may have overshadowed earlier societal debates and changes by other demographic factors, like age, class and race. A continuing question in this revolution is whether women are making gains in reducing their time spent in more routine, onerous and labor-intensive aspects of daily life, particularly those associated with maintaining one's family and household. An important question in this debate concerns how much these gender inequalities are felt by women as they engage in these largely gender-segregated daily activities.

Time-diary Studies: Until recently, most measures of the time men and women spend in work, family and free time settings were based on simple survey estimates made by people of the hours they spent at work, housework or TV (e.g., “How many hours did you work last week?”), rather than on more detailed accounts of daily activity based on-site observation, electronic pagers or time diaries. The great value of these time-diary accounts (Szalai, 1972) is that workers report on all their daily activities in their own words, and not just general survey questions about their work, housework or TV time. In accounting for all their time in time diaries, for example, survey respondents are less prone to encounter problems of memory loss, stereotyping, self-projection or double counting of time than when they respond to general time questions.

Thus, time diaries represent a major scientific advance in addressing these gender isues over this last half century. Diaries provide a simple and reliable measurement of the time both women and men spend on these core activities, as first reported in national time-use studies conducted by academic research centers at the University of Michigan in 1965-75 and at the University of Maryland since 1985 (Juster \& Stafford, 1985; Robinson \& Godbey, 1999). Moreover, these data have now been harmonized and archived internationally at timeuse.org at the Time-Use Research Centre at the University of Oxford (Gershuny, 2012), and these diary data have documented a largely silent revolution toward gender equity in performing household and family care tasks-not only in the United States but in more than other Western countries as well. In the US, for example, men now report nearly $40 \%$ of house and family care, nearly double the roughly $20 \%$ reported in 1965

These efforts to quantify the societal division of labor have been further updated and expanded since 2003 with the advent of the American Time-Use Survey (ATUS). The ATUS has been conducting daily time-diary studies as collected from large national probability samples by the US Census Bureau to document how American daily life is changing in real time, and this continuous project has now accumulated diary data from more than 130,000 respondents aged 15 and older since 2003.

Subjective Time Measures: But what about the psychological consequences of these time changes? How do women and men differ in how they feel as they go about their rounds of daily activities? To aid in the interpretation of such diary accounts, more than 8000 of these ATUS respondents in 2010 and 2012 were also asked how they felt while they were engaged in these activities, using a Social Well-Being (SWB) index as developed by Krueger et al. (2009) and Kahneman et al. (2004). That now makes it possible to identify which daily activities bring Americans most positive feelings_-and those which seem to most negatively affect the momentary quality of their lives (QOL) on six separate psychological factors or states. The full range of these six QOL factors, as rated by more than 37,000 ATUS respondents, ran from 6.0 as having the maximum of that state and 0.0 having none of that state. Those six psychological states are meaningful, sad, tired, stress, pain and happy. Since ratings on the "meaningful" item failed to correlate significantly with most of the other five, they have been excluded from further analysis in Table 1 and Table 2.

\section{Results}

Most prominently, it can first be seen in the five columns of Table 1 that these psychological ratings are overwhelmingly positive, despite the space respondents are provided to record any negative experiences. Thus, less than $30 \%$ of respondents report the minimum (zero) feelings of being sad or in pain, and more than half report zero stress or at the top two rungs for happiness. Many more respondents do report being tired, but even a third of respondents report a zero on that scale. Thus, relatively few people say they experience even mild discomfort from engaging in their daily activities, as reflected in the mean scale scores of only 0.61 to 2.20 (out of 6.0) for the first four negative states, compared to the mean 4.3 for the single positive state of happy. As in the earlier academic national diary studies that asked such subjective time questions, then, the first good news is that most respondents do not describe their everyday life in critical terms. We will turn shortly to some specific activities that do bring about significant exceptions to this conclusion, but we first turn to the methods that lead to these 
Table 1. Percent of respondents giving each SWB scale score ( $\mathrm{n}>38,000$ ratings on each state).

\begin{tabular}{cccccc}
\hline SCORE & SAD & PAIN & TIRED & STRESS & *HAPPY \\
\hline 0 & $76 \%$ & $70 \%$ & $30 \%$ & $51 \%$ & $5 \%$ \\
1 & 7 & 7 & 9 & 11 & 6 \\
2 & 5 & 6 & 14 & 12 & 16 \\
3 & 5 & 6 & 17 & 11 & 23 \\
4 & 3 & 5 & 19 & 7 & 30 \\
5 & 3 & 3 & 4 & 4 & $100 \%$ \\
MEAN (0 - 6) & 2 & 3 & 7 & $100 \%$ & 4.31 \\
Men & $100 \%$ & $100 \%$ & $100 \%$ & 1.32 & 4.25 \\
(Women-Men) F= & 0.64 & 0.94 & 2.20 & 1.23 & 4.37 \\
\hline
\end{tabular}

Note: * Reverse scored with the other items, where 6 is the most positive and 0 most negative.

conclusions.

This analysis focuses on perhaps the two most central of these feelings, with the problem that four of these five feeling states are phrased in the negative. Women score quite significantly higher on all four of them (particularly for feeling tired), as shown by the very large F-values (well above the 0.001 level of chance) at the bottom of Table 1 . That means that by definition women would have to score more negatively than men on an overall five-item measure of feelings about their daily life activities. Moreover, three of these negative four states (pain, tired and stress) refer more to activity than to pure emotion. The remaining two-sad and happy-thus have more to recommend them as an overall measure of feelings. First, both refer specifically to purely emotional states. Second, one is positive and one is negative, offsetting the unfortunate gender tendency in how ATUS respondents describe their feelings. Third, they are virtual antonyms, meaning that they provide a more reliable (two-item) indicator of that state.

Perhaps the main virtue of this simple happy-sad index is that it minimizes any overall gender difference apparent across the full five items. Both men and women average 3.7 on the happy-sad scale. That allows one to highlight any "pure" gender difference, namely one that occurs for the same activity.

Moreover, separate analyses show that this two-item antonym scale correlates very highly (0.77) with the longer (and overly negative) five-item scale, so that we are not losing much in terms of interpretations of their correlations with activities, demographics or other factors. This is verified in a separate and more detailed analysis of the five-item.

Thus, developing the simple index proceeded as follows. One first takes the average score on the ratings for the "happy" rating and subtracts from it the average for the "sad" rating. This generates an average rating of about 3.7 for each gender (or 7.4 for the two genders when added together, as in the first column of Table 2). Thus, that is the average column rating as it relates to all activities and to both genders. To put these smaller gender differences in fuller context, they are shown separately in the right-hand side of Table 2 in relation to the much larger (and ordered) differences by activity. This order, in the first column of Table 2, can be seen as running from values below 3.0 — for medical/health care and job seeking — to values above 10.0 —-for playing with or reading to children (again as combined for men and women together).

We turn first to these larger activity differences for both genders combined as shown in the first column (left side) of Table 2. Note that (predominantly) free-time activities are noted in bolder letters to distinguish their differences from more necessary, obligatory or directly productive activities, like sleep or family care:

Activity Differences: Thus, this rough free-obligatory activity distinction (which is not absolute can often become blurred) becomes useful in first finding that seven of the nine most positive (more enjoyable) activities in 
Table 2. Happy-sad ratings (From ATUS 2010-12).

\begin{tabular}{|c|c|c|c|c|}
\hline \multicolumn{5}{|c|}{ FREE-TIME ACTIVITIES IN BOLD } \\
\hline \multicolumn{2}{|c|}{ ALL (MALE + FEMALE) } & \multirow{2}{*}{$\begin{array}{c}\text { SAMPLE SIZE }(\mathrm{n}=) \\
326\end{array}$} & \multicolumn{2}{|c|}{ MEN/WOMEN } \\
\hline 10.4 & KID PLAY/READ & & 5.45 .0 & KID PLAY/READ \\
\hline 9.1 & VOLUNTEER & 283 & 4.54 .6 & VOLUNTEER \\
\hline 8.9 & RELIGION & 443 & 4.64 .3 & RELIGION \\
\hline 8.7 & FITNESS & 607 & 4.24 .5 & FITNESS \\
\hline 8.7 & WALK PET & 181 & 4.24 .5 & WALK PET \\
\hline 8.6 & BABY CARE & 945 & 4.44 .2 & BABY CARE \\
\hline 8.5 & GAMES & 311 & 4.14 .4 & GAMES \\
\hline 8.4 & SOCIALIZING & 1489 & 4.14 .3 & SOCIALIZING \\
\hline 8.4 & AUDIO & 107 & 4.14 .3 & AUDIO \\
\hline 7.7 & ADULT CARE & 86 & 4.33 .4 & ADULT CARE \\
\hline 7.6 & TRAVEL & 7208 & 3.73 .9 & TRAVEL \\
\hline 7.5 & YARD/GARDEN & 504 & 3.63 .9 & YARD/GARDEN \\
\hline 7.5 & EAT MEALS & 5813 & 3.63 .9 & EAT MEALS \\
\hline 7.4 & PREPARE MEALS & 2340 & 3.73 .7 & PREPARE MEALS \\
\hline 7.3 & READING & 626 & 3.63 .7 & READING \\
\hline 7.2 & HELP NEIGHBOR & 381 & 3.53 .7 & HELP NEIGHBOR \\
\hline 7.1 & PET CARE & 288 & 3.53 .6 & PET CARE \\
\hline 6.8 & COMMUTE & 1763 & 3.43 .4 & COMMUTE \\
\hline 6.8 & PHONE & 396 & 3.33 .5 & PHONE \\
\hline 6.8 & TV & 3128 & 3.43 .4 & TV \\
\hline 6.8 & MAIL, EMAIL & 293 & 3.43 .4 & MAIL EMAIL \\
\hline 6.8 & RETAIL SHOP & 738 & 3.43 .4 & RETAIL SHOP \\
\hline 6.7 & RELAX & 715 & $3.23 ; 5$ & RELAX \\
\hline 6.6 & HH PLANING & 469 & 3630 & HH PLAN \\
\hline 6.4 & COMPUTER & 374 & 3.33 .1 & COMPUTER \\
\hline 6.3 & MAIN JOB & 2303 & 3.13 .2 & MAIN JOB \\
\hline 6.3 & CLEAN HOUSE & 6739 & 3.03 .3 & CLEAN HOUSE \\
\hline 6.3 & GROCERY SHOP & 374 & 3.13 .2 & GROCERIES \\
\hline 5.9 & CAR REPAIR & 85 & 2.93 .0 & CAR REPAIR \\
\hline 5.9 & $2^{\mathrm{ND}} \mathrm{JOB}$ & 78 & 3.82 .1 & $2^{\mathrm{ND}} \mathrm{JOB}$ \\
\hline 5.5 & LAUNDRY & 564 & 2.53 .0 & LAUNDRY \\
\hline 5.5 & EDUC & 309 & 2.53 .0 & EDUC \\
\hline 4.5 & SCHOOLWORK & 174 & 2.02 .5 & SCHOOLWORK \\
\hline 4.3 & PAY BILLS & 94 & 2.61 .7 & PAY BILLS \\
\hline 3.6 & MEDICAL CARE & 84 & 1.71 .9 & MEDICAL CARE \\
\hline 2.9 & JOB SEARCH & 61 & 0.82 .1 & JOB SEARCH \\
\hline 2.5 & SICK CARE & 212 & 1.11 .4 & SICK CARE \\
\hline
\end{tabular}


the first column of Table 2 fall into the purer free-time category. These seven are for 1) volunteering, 2) various religious activities, 3) fitness and sports (mainly walking), 4) outings/play with pets, 5) games, 6) socializing (especially at parties), and 7) audio (music/radio) listening. The final two of these highest rated activities in Table 2 involved children, namely the parental activities of 1) reading and playing with children (with its highest "happy-sad" rating of above 10.0), and 2) physical/bodily (baby) care for children (8.6).

Next on the list—at around the midpoint of 7.6 in the first column of Table 2-are five more "obligatory" activities, including household adult care, yard/outdoor upkeep, and both preparing and eating meals. It also includes the travel involved in getting to and from various non-work (except work). One can note further below in Table 2 that these work-travel or work-commute ratings rate notably lower on this scale (6.8), reflecting an important and larger finding about travel that, no matter how similar they may be in the length, effort or skill involved, travel ratings are neither constant nor homogeneous but do vary markedly depending on the purpose of the trip. Thus, trips for religion and socializing are rated well above the overall average rating of 7.6, while trips for household tasks and medical care are well below the commute average figure of 6.8 .

The next set of (now slightly-below average enjoyment) activities does include the free-time activity of reading, along with the more productive activities of helping neighbors and others and with the feeding and other physical care of pets. Further below-below average ratings follow, such as for commuting (noted above), for relaxing, and for store shopping for (non-food) durable goods ("retail therapy").

Notably, at this low level is the rating for the most prominent of free-time activities-watching television (which consumes almost half of peoples' free time). In about that same more negative region are other communication and media activities - telephone calls, handling household mail and email, other computer use, household planning/organizing and taking education classes (the latter being notably higher than the ratings for doing its attendant schoolwork/homework).

As in previous studies of diary-based feelings (Robinson \& Godbey, 1999), the routine household tasks of house cleaning, grocery shopping, laundry, repairs and paying bills begin to define the least pleasant of Table 2 daily activities, with average ratings dropping from 6.3 to 4.3. However, these still rate higher than those activities at the absolute bottom of daily life, namely for self and professional medical/health care and for searching for a job or work.

Perhaps the most distressing rating in Table 2 not discussed above, however, is for a most prominent and defining feature of daily life, namely one's job or employment. Its overall rating of 6.3 puts it at the same level as household chores, which are usually afforded minimal social status. These low ratings for work are decreased even further if second jobs are included. It needs to be noted that that this low Table 2 enjoyment rating for work is not supported by traditional survey studies using more accepted ways and trends in measuring job satisfaction. Nonetheless, paid work still may represent the most alarming rating in the table.

Gender Differences: As noted at the outset, the differences by gender on the right hand side of Table 2 pale in comparison to those by activity. Perhaps most importantly, they do not point to women feeling dramatically less positive while doing them than do men. Thus, it can be seen that women report being a little happier than men while doing laundry or cleaning house. Mothers do report less happiness when playing with or monitoring children than fathers, but child play still remains their most favorite activity. Women also report feeling better when taking classes and doing its related schoolwork, which may explain why their academic performance has outpaced men's. One prominent activity they do dread more than men is paying the bills, one of the few significant gender differences in the table.

Overall, then, women may remain stuck with doing most of these routine and least favorite of daily parts of the day in Table 2, but they don't rate doing it lower than do men. It may still come as small comfort that men's rating of paid work fares no better than women's rating of most housework, but that does not further take into account that women may also bear the burden of being expected to perform these functions, as well to monitor them.

\section{Summary and Conclusion}

Using this new and simple two-item SBW scale, then, these national ATUS ratings of activities in Table 2 largely replicate the general feelings about engaging in various daily activities identified in previous time studies in Robinson (1993) and in Gershuny (2012), which used simpler enjoyment scales as their well-being measure. Few respondents fall below the middle, or in the more negative range, of these rating scales. Social and visiting 
activity, interactive activities with children and religious/volunteer activities remain at the top of the list of favorite daily activities as rated in the "real time" context of the diary, as well as in general. Routine household tasks and attending to medical and other personal needs rate at the bottom (That also tends to be the ranking reported from the community study as reported in Table 3 of Krueger et al., 2009).

What may be most interesting, surprising, important—and troubling —in these new ATUS ratings, however, is the notably lower SWB ratings given to paid work activities. This may reflect a disturbing trend about work (especially if it includes moonlighting on second jobs and job searches), which may be taken simply as a way to keep one's basic household needs afloat. The finding that these ratings are so far below the norm remains cause for some alarm. These findings are also at odds with several responses US workers give to general survey questions about the role and importance of work in their lives (Robinson \& Martin, 2008; Robinson \& Godbey, 1999).

Of further concern is the below average rating given to Americans' most prevalent free-time activity of TV viewing. TV may serve to offset the even-lower rated activity of paid work, but it still rates notably lower than more social and active choices in spending one's free-time. Earlier results from Kubey and Csikszentmihalyi (1990) suggested TV was not that much lower in enjoyment ratings than other activities, but that TV was more deficient on adjectives like "challenging" and "alertness" (not included in the present SWB ratings). Thus, both findings suggest that engaging in more active free-time activities could be one road to improving America's collective SWB.

At the same time, these results do raise questions about the efficacy and efficiency of the five-item SWB approach employed in the ATUS, echoing many of the concerns raised by earlier results from the Princeton team, as raised by Diener and Tay (2014), Michelson (2009), Bittman (2009), Juster (2009) and Gershuny (2009). One step to resolve some of the discrepancies, particularly about work feelings, would be to replicate the simpler enjoyment ratings used in earlier diary surveys.

\section{References}

Aguiar, M., \& Hurst, E. (2009). A Summary of Trends in American Time Allocation. Social Indicators Research, 93, 70-80.

Diener, E., \& Tay, L. (2014). The Day Reconstruction Method: (DRM): A Review. Social Indicators Research, 116, 255267. http://dx.doi.org/10.1007/s11205-013-0279-x

Gershuny, J. (2009). Comment on Krueger and Colleagues. Social Indicators Research, 93, 23-26. http://dx.doi.org/10.1007/s11205-008-9379-4

Gershuny, J. (2012). National Utility: Measuring the Enjoyment of Activities. European Sociological Review, 10, 1093 1-17.

Juster, T. (2009). Some Perspectives on the Study of Time Use. Social Indicators Research, 93, 19-21. http://dx.doi.org/10.1007/s11205-008-9418-1

Juster, T. and Frank, S. (1985). Time, Goods, and Well-Being. Ann Arbor: Survey Research Center, Institute for Social Research, University of Michigan.

Kahneman, D., Krueger, A. B., Schkade, D. A., Schwarz, N., \& Stone, A. A. (2004). A Survey Method for Characterizing Daily Life Experience: The Day Reconstruction Method. Science, 306, 1776-1780.

http://dx.doi.org/10.1126/science.1103572

Krueger, A. et al. (2009). Comparing Time Use and Subjective Well Being in Two Countries. Social Indicators Research, 93, 1-17.

Michelson, W. (2009). Adding Affect to Time Diary Accounts 31-32. Social Indicators Research, 93, 31-32. http://dx.doi.org/10.1007/s11205-008-9363-z

Robinson, J. (1993). As We Like It. American Demographics, 15, 44-48.

Robinson, J. (2014). As We (Still) Like It: Socializing, Religion, Kids Remain Our Favorite Daily Activities. Working Paper No. PWP-MPRC-2013-024. Maryland Population Research Center. http://papers.ccpr.ucla.edu/papers/PWP-MPRC-2013-024/PWP-MPRC-2013-024.pdf

Robinson, J., \& Martin, S. (2008). What Do Happy People Do? Social Indicators Research, 89, 565-571. http://dx.doi.org/10.1007/s11205-008-9296-6

Robinson, J., \& Godbey, G. (1999). Time for Life: The Surprising Ways Americans Use Their Time (2nd ed.). University Park, PA: Pennsylvania Sate University Press.

Robinson, J., \& Martin, S. (2009). Comments on Krueger Presentation. Social Indicators Research, 93, 23-27. http://dx.doi.org/10.1007/s11205-008-9366-9

Szalai, A. (ed.) (1972). The Use of Time: Daily Activities of Urban and Suburban Populations in Twelve Countries. The Hague, Paris: Mouton. 